\title{
Detection of Epstein-Barr virus genomes in Hodgkin's disease: Relation to age
}

\author{
R F Jarrett, A Gallagher, D B Jones, F E Alexander, A S Krajewski, A Kelsey, J Adams, \\ B Angus, S Gledhill, D H Wright, R A Cartwright, D E Onions
}

Leukaemia Research Fund Virus Centre, Department of Veterinary Pathology, University of Glasgow, Bearsden Road, Glasgow G61 1QH R F Jarrett A Gallagher

$S$ Gledhill

D E Onions

University

Department of

Pathology,

Southampton Genera

Hospital,

Southampton

D B Jones

D H Wright

Leukaemia Research

Fund Centre for

Clinical Epidemiology

Southampton Site,

University

Department of

Medical Oncology,

Royal Southants

Hospital

F E Alexander

Department of

Pathology, University

Medical School,

Edinburgh

A S Krajewski

Department of

Histopathology, Royal

Manchester Children's

Hospital

A Kelsey

J Adams

School of Pathological Sciences, University of Newcastle Upon Tyne $B$ Angus

Leukaemia Research Fund Centre for Clinical

Epidemiology, Leeds R A Cartwright

Correspondence to: R F Jarrett

Accepted for publication 22 May 1991

\begin{abstract}
An investigation as to whether any particular subgroup of patients with Hodgkin's disease was particularly likely to be Epstein-Barr virus (EBV) genome positive was made on samples from 95 patients. These were grouped according to age and Hodgkin's disease subtype, and analysed using Southern blot analysis. Most samples from children or adults aged 50 years or over contained detectable EBV genomes; samples from young adults were only rarely positive. The differences in EBV positivity by age were highly significant, but there was no significant association between EBV and histological subtype after allowing for the effect of age.

The results support the hypothesis that Hodgkin's disease in different age groups may have different aetiologies, and suggest that EBV does have a pathogenetic role in Hodgkin's disease in children and older age groups.
\end{abstract}

Accumulating evidence suggests that the Epstein-Barr virus (EBV) has a role in the pathogenesis of Hodgkin's disease. Initial studies found raised antibody titres to EBV in such patients, ${ }^{1-3}$ and later it was shown that increased antibody titres occurred before Hodgkin's disease was diagnosed. ${ }^{4}$ Using sensitive molecular probes, EBV genomes have been detected in tumour biopsy specimens from a proportion of cases..$^{5-13}$ The EBV genomes contained within the tumours have been shown to be clonal, indicating that the EBV infected population has arisen from a single infected cell..$^{59-1113}$ Furthermore, the EBV genomes have been localised to ReedSternberg cells by in situ hybridisation, ${ }^{79} 1014$ and recent studies have shown that the EBV latent genes EBER 1 and LMP are expressed by Reed-Sternberg cells (unpublished observations).$^{14} 15$ These latter observations support the argument that EBV has an aetiological role in Hodgkin's disease and is not simply reactivated during the course of the disease.

A consistent feature of the molecular studies is that EBV is detectable in only a proportion of cases. ${ }^{5-13}$ This figure varies from $18-41 \%$ using Southern blot analysis. ${ }^{5-11} 13$ The failure to detect EBV in all cases does not detract from the importance of the viral association as the pathological and epidemiological features of Hodgkin's disease suggest that it is a heterogeneous condition. The disease is usually subdivided histologically into the four subtypes described in the Rye classification. ${ }^{16}$ Epidemiologically, however, three groups of cases can be distinguished and these correspond to the age groups 0-14 years, 15-34 years, and 50 years and over. ${ }^{17}$ There is some concordance between these two methods of subgrouping Hodgkin's-for example, nodular sclerosis Hodgkin's disease (HDNS) accounts for the peak incidence in the age range 15-34 years and mixed cellularity Hodgkin's disease (HDMC) shows an increasing incidence with increasing age. ${ }^{18}$

Most groups studying the role of EBV in Hodgkin's disease have reported the subtype distribution of their cases. Using Southern blot analysis, four groups, including ourselves, have found a lower proportion of EBV genome positive cases within the HDNS subtype when compared with HDMC or all the other subtypes grouped together. These differences, however, have not reached statistical significance. ${ }^{561113}$ Significant associations may have been masked either by the small numbers of cases included in some studies or the subjectivity of the histological classification system used. In a larger series of cases Pallesen et al, using immunohistochemistry, found a significant association between EBV positivity and HDMC. ${ }^{15}$

In our initial study of the association between EBV and Hodgkin's disease it was found tht EBV positivity was significantly associated with increasing age. ${ }^{13}$ It was also noted that the only two cases aged younger than 15 years in our study were EBV positive. ${ }^{13}$

The purpose of the present study, therefore, was to determine whether the association between age and EBV genome positivity remained following the analysis of a larger number of cases in the age groups 50 years and over and younger than 15 years. Cases of HDMC disease were also positively selected to ascertain whether EBV was significantly associated with this histological subtype. We also EBV subtyped the positive cases to extend our previous observation that the EBV genomes were of subtype $\mathrm{A},{ }^{13}$ which is thought to be the prevalent strain of EBV in the United Kingdom. ${ }^{19}$

\section{Methods}

Samples of lymph node or spleen from a total of 95 cases of Hodgkin's disease were examined. Thirty five of these have been reported previously. ${ }^{13}$ The cases were grouped accord- 
EBV positivity by age and histological subtype

\begin{tabular}{|c|c|c|c|c|c|c|c|c|}
\hline \multirow[b]{3}{*}{ Selection procedure } & \multicolumn{8}{|c|}{ Age and histological subtype } \\
\hline & \multirow[b]{2}{*}{ Paediatric } & \multicolumn{3}{|l|}{$15-34 y$} & \multirow[b]{2}{*}{$35-49 y$} & \multicolumn{3}{|l|}{$>50 y$} \\
\hline & & $H D N S$ & $H D M C$ & Other & & $H D N S$ & $H D M C$ & Other \\
\hline \multirow{2}{*}{$\begin{array}{l}\text { Non-selected } \\
\text { Selected for age } \\
\text { Selected for age and subtype }\end{array}$} & \multirow[t]{2}{*}{$\begin{array}{l}2 / 2 \\
5 / 11\end{array}$} & \multirow[t]{2}{*}{$2 / 22$} & $2 / 4$ & \multirow[t]{2}{*}{$0 / 2$} & \multirow[t]{2}{*}{$3 / 8$} & \multirow[t]{2}{*}{$\begin{array}{c}6 / 7 \\
10 / 16\end{array}$} & \multirow[t]{2}{*}{$\begin{array}{l}2 / 2 \\
7 / 11\end{array}$} & \multirow{2}{*}{$2 / 2$} \\
\hline & & & $2 / 8$ & & & & & \\
\hline Total & $7 / 13$ & $2 / 22$ & $4 / 12$ & $0 / 2$ & $3 / 8$ & $16 / 23$ & $9 / 13$ & $2 / 2$ \\
\hline
\end{tabular}

"Other" includes cases of lymphocyte predominance and lymphocyte depleted Hodgkin's disease. Only non-selected cases or those selected on the basis of age were included in the age analysis. The histological subtypes of cases in the young adults and the $35-49$ year age brackets are not given as the numbers in these groups were small; positive results were obtained from both HDMC and HDNS cases.

ing to age at date of biopsy and histological subtype (table). Forty seven of the samples were from non-selected patients with Hodgkin's disease; 40 were selected on the basis of age; and a further eight were selected for both age and subtype to increase the numbers in appropriate groups. These particular age groups were chosen on the basis of the epidemiological data cited above. ${ }^{17}$ Cases aged 35 to 49 years were not specifically selected as they are thought to represent an overlap between the young adult (15-34 years) and older (50 years and over) age groups. Cases aged less than 15 years were classified as paediatric. Control samples included 35 random lymph nodes, 12 reactive lymph nodes from paediatric patients, and 14 lymph nodes from patients with non-Hodgkin's lymphoma aged over 60 ; the latter samples have been reported previously. ${ }^{13}$

DNA was extracted from all samples using standard procedures, and Southern blot hybridisation was performed as described elsewhere. $^{20}$ Southern blot hybridisation was chosen as the method of analysis in these studies as EBV genomes are only rarely detected in non-Hodgkin's lymphomas using this technique. ${ }^{621}$ Notable exceptions to the above are Burkitt's lymphoma and lymphomas in the immunosuppressed..$^{22-26}$ To assess the sensitivity of our Southern blot technique we analysed $10 \mu \mathrm{g}$ of serial 10-fold dilutions of DNA from the RAJI cell line. This cell line is estimated to contain 45 copies of the EBV genome. ${ }^{27}$

Two EBV probes were used. All samples were hybridised with the $B a m H I-W$ fragment which represents the internal repeat of EBV and therefore provides a sensitive indicator for its presence. ${ }^{28}$ For this analysis $10 \mu \mathrm{g}$ of DNA were digested with the restriction endonuclease BamHI.

Twenty six of the positive samples, including samples from all groups, were subsequently hybridised with the EcoRI-D fragment of EBV. ${ }^{28}$ This probe contains the terminal repeats of EBV and by virtue of this can be used to assess the clonality of the infected population. ${ }^{29}$ For this analysis $20 \mu \mathrm{g}$ of DNA were double-digested with BamHI and EcoRI. Following digestion of circular EBV genomes with $B a m H I$ and $E c o R I$, the EcoRI-D probe detects two fragments. One is a fragment of 6.5 kilobase pairs which is of constant size in all
EBV genomes; the second varies in size from one viral genome to another, depending on the number of terminal repeat sequences which it contains. If the cell population infected with EBV has arisen from a single cell, infected at a low multiplicity of infection, then all the genomes will contain identical numbers of terminal repeats. ${ }^{29}$ This will result in the visualisation of a single, discrete band in addition to the 6.5 kilobase pair band.

In the above analyses DNA from placenta and from the infected cell line, B95-8, were used as negative and positive controls, respectively.

The polymerase chain reaction (PCR) was used to determine whether the EBV genomes detected were of subtype A or B. The primers used in this assay and the reaction conditions have been described elsewhere. ${ }^{13} 30$

Logistic regression was applied using GENSTAT V. ${ }^{31}$ Statistical testing used analysis of deviance and the asymptotic $\chi^{2}$ distribution for the deviance difference under the null hypothesis. Each analysis was applied to the largest number of results which were appropriate from the table. In some analyses HDMC cases were grouped together with lympocyte predominance and lymphocyte depleted cases in a category designated all other subtypes (HDAOS).

\section{Results}

SENSITIVITY OF SOUTHERN BLOT ANALYSIS FOR THE DETECTION OF EBV

Following Southern blotting and hybridisation with the BamHI-W probe, EBV DNA was detectable in $10 \mu \mathrm{g}$ of the $10^{-4}$ dilution of RAJI DNA (data not shown). This suggests that we can detect a single EBV genome present in less than $0.45 \%$ of the cells in any $10 \mu \mathrm{g}$ sample. This figure is only an approximate value as this calculation does not allow for the variation in the number of $B a m H I-W$ repeat sequences (usually seven to 12 ) present in different viral genomes.

\section{EBV IN PATIENTS AND CONTROLS}

The results are summarised in the table. A total of 43 positive samples were identified; in these a fragment of about $3 \cdot 1$ kilobase pairs, which hybridised with the Bam $H I-W$ probe, was detectable by autoradiography following two days of exposure. Seventeen of the 47 non- 
Figure 1 Southern blot analysis of representative, positive Hodgkin's disease samples using the BamHIW probe. Case 37: HDMC aged 14; case $74:$ HDNS aged 82; case 80: HDMC aged $54 ;$ case $85:$ HDMC aged $75 ;$ case $86 ; H D M C$ aged 72; case 88: HDLP aged 53. Additional bands visualised in B95-8, the positive control, represent the fragments flanking the BamHI-W repeat sequence.

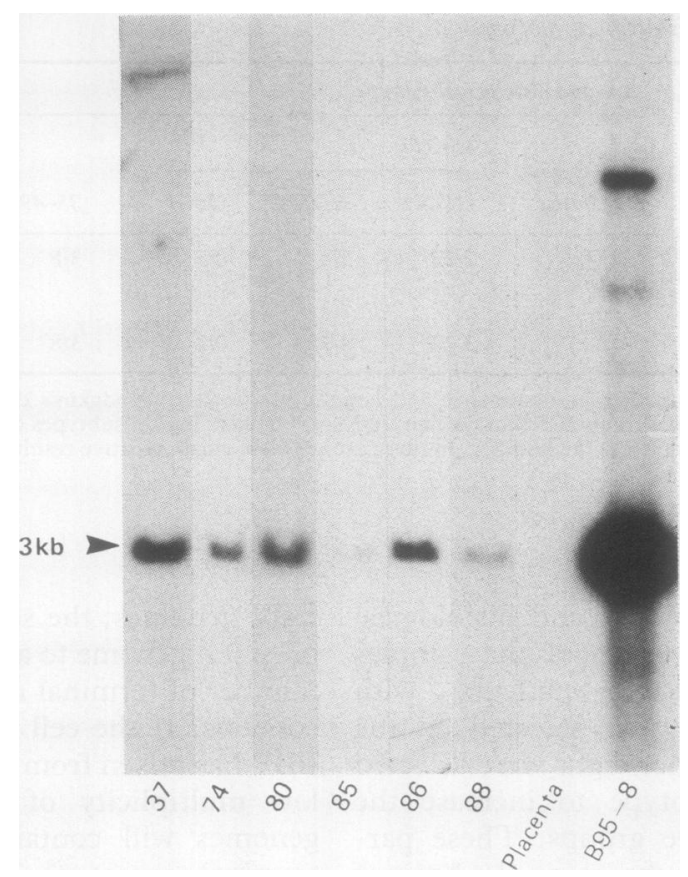

selected cases were EBV genome positive (fig 1). Two of the random lymph nodes were EBV positive, one was a secondary nasopharnygeal carcinoma and the other was a B-cell immunoblastic lymphoma; both malignancies have been associated with EBV. ${ }^{61-23}$ One of the 14 samples from patients over the age of 60 with non-Hodgkin's lymphoma was positive. This sample, which was also from a B cell immunoblastic lymphoma, gave a weakly positive autoradiographic signal following a 10 day exposure of the Southern blot. ${ }^{13}$ None of the reactive nodes from paediatric patients contained detectable EBV DNA.

EFFECT OF AGE

In the oldest age group 27 of the $38(71 \%)$ cases of Hodgkin's disease were positive and in the

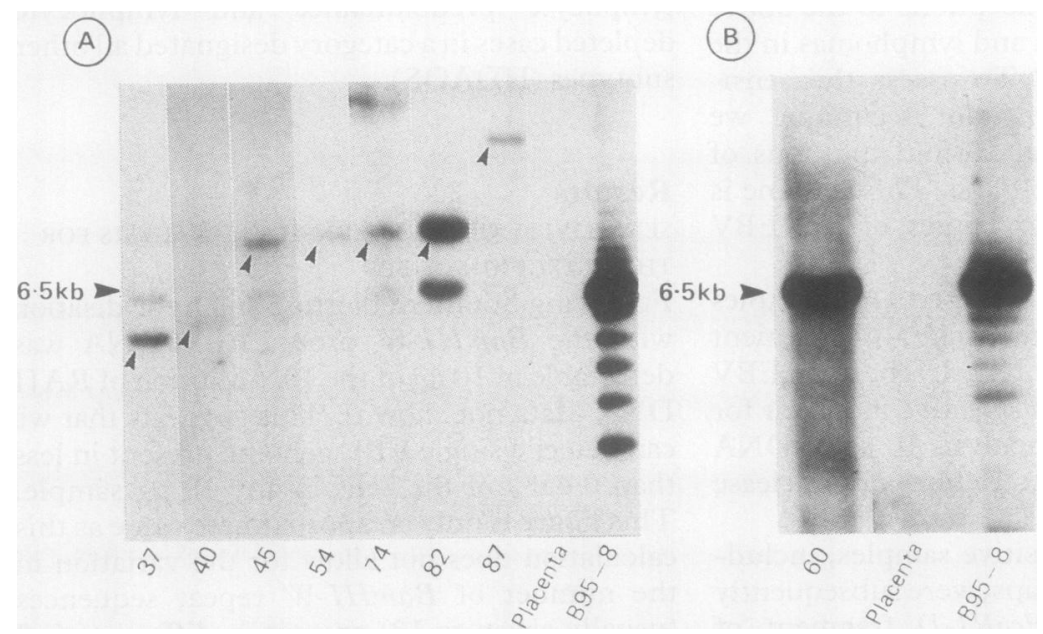

Figure 2 Panel A: Southern blot analysis of representative EBV genome positive Hodgkin's disease samples using the EcoRI-D probe. Case 37: HDMC aged 14; case 40:HDMC aged 5; case 45: HDNS aged 24; case 54:HDMC aged 31 ; case $74 ;$ 40: $H D M C$ aged 5; case $45: H D N S$ aged $24 ;$ case $54: H D M C$ aged 31 ; case $74 ;$
HDNS aged $82 ;$ case $82: H D M C$ aged 78 ; case $87: H D$ lymphocyte predominance aged 65 . In EcoRI and BamHI double-digested samples containing EBV DNA an invariant band of 6.5 kilobase pairs is seen (just visible in case 54 ). In the Hodgkin's disease samples there is a single additional band of variable size (arrowed). Panel $B$ Southern blot analysis of case 60, HDNS aged 59, using the EcoRI-D probe. In this case only the 6.5 kilobase pair fragment is detected. The ladder of fragments seen in the positive control lanes (B95-8) indicates the presence of linear EBV genomes and episomal forms with different numbers of terminal repeats. ${ }^{29}$ paediatric group seven of the $13(54 \%)$ samples were EBV positive. In contrast to these results, only four of the $28(<15 \%)$ cases in the young adults aged 15 to 34 were positive. Samples which were selected on the basis of both age and subtype were excluded from the above analyses. EBV was detected in three of the eight samples from patients in the 35-49 year old age range; this proportion of EBV positive cases is intermediate between that for the young adult and older cases.

Statistical testing of the above results, performed without adjustment for disease subtype, indicated a trend for increasing EBV positivity with age: $\chi^{2}=15 \cdot 7$ on 1 degree of freedom; $p<0.001$. The departure from linear trend was tested by adding a quadratic term to the model: $\chi^{2}=9.6$ on 1 degree of freedom; $\mathrm{p}<0.01$. This indicates that the trend for an increase in positivity with increasing age is not linear and infers that as a group the paediatric cases are different. The age groups $15-34$ and 50 years and over were then compared after adjustment for subtype. The finding of increased positivity in the older age group was highly significant: $\chi^{2}=24.8$ on 1 degree of freedom; $\mathrm{p}<0.0001$.

\section{EFFECT OF HISTOLOGICAL SUBTYPE}

There was a slight excess of positive cases in the HDMC group (table). This was statistically tested in the two age groups $15-34$ and 50 years and over; all cases in these age ranges were included and adjustment for age was made. The effect of subtype was not significant when either HDNS, HDMC, and other subtypes were compared $\left(\chi^{2}=0.73\right.$ on 2 degrees of freedom; $\mathrm{p}>0.5)$, or when HDNS and HDAOS cases were compared $\left(\chi^{2}=0.73\right.$ on 1 degree of freedom; $p>0.5)$. In the 15-34 year age group there was an excess of positive cases in the HDAOS group, but this did not reach significance (Fisher's exact test, 1 tail; $\mathrm{p}=$ $0 \cdot 14)$.

CLONALITY OF EBV GENOMES

The clonality of the EBV genomes in 26 of the positive cases was assessed by hydridisation with the $E c o R I-D$ probe, as outlined above. In 25 of the 26 cases examined a single discrete fragment, which varied in size from case to case, was detected in addition to the invariant 6.5 kilobase pair fragment (fig 2A). This suggests that the cell population infected with EBV in these cases is a clonal expansion of a single infected cell. In the remaining sample, which was from a 59 year old man with HDNS (case 60), an intense invariant band at 6.5 kilobase pairs was present, but no additional bands were visualised (fig 2B). A similar result was obtained when this sample was digested with BamHI alone; the latter observation indicates that the fragment containing the terminal repeats was not comigrating with the 6.5 kilobase pair band in the original analysis.

\section{EBV SUBTYPE}

Thirty of the EBV positive samples were EBV subtyped using a PCR strategy; in all cases the genomes were subtype A (data not shown). 


\section{Discussion}

In this study we detected EBV genomes in tumour samples from most of the paediatric and older patients with Hodgkin's disease. This contrasted with the case in young adults in which EBV genomes were detected infrequently. Statistical analysis showed that the association between age and EBV was highly significant. Analysis of control samples did not show an excess of EBV positivity in lymph nodes from paediatric or older cases. No additional significant association between EBV positivity and Hodgkin's disease subtype emerged.

Most groups who have studied the association between EBV and Hodgkin's disease using Southern blot analysis have not examined the association between age and EBV positivity. Two exceptions to this are Boiocchi et al ${ }^{11}$ and Libetta et al. ${ }^{12}$ Boiocchi et al did not find an association between age and EBV positivity, but only five older cases were examined out of a total of 17. In the study by Libetta et al there was an excess of positive cases in older patients compared with children and young adults, but this was not significant. The results of this latter study are difficult to interpret as in over half of the cases which they considered EBV positive the EBV BamHI-W probe hybridised to a DNA fragment of unexpected size.

The possibility of an association between EBV and Hodgkin's disease subtype has been addressed by most studies. In keeping with our results three other groups have reported a slight excess of positivity among the HDMC or HDAOS cases, but this did not reach significance. ${ }^{5611}$ Pallesen et al, using immunohistochemistry, did find a significant association between expression of EBV and HDMC. ${ }^{15}$ Our results suggest that subtype should not be analysed separately from age as age is likely to be an important confounding variable. This is of particular relevance here as the relative incidence of HDMC is greater in older patients with Hodgkin's disease. ${ }^{18}$

In the present study Southern blot analysis was used to detect EBV genomes. Recently the PCR has been used to look for EBV in Hodgkin's disease tumours and this has resulted in the detection of larger proportions $(50 \%$ and $58 \%)$ of positive samples. ${ }^{32}{ }^{33}$ Using Southern blot hybridisation and the BamHI$W$ probe we detected a single EBV genome in about $0.45 \%$ of the sample; this technique should therefore be sufficiently sensitive to detect EBV in most cases of Hodgkin's disease if the EBV genomes are present in Reed-Sternberg cells and their mononuclear equivalents. Indirect support from this comes from the results of an earlier study in which we did not find a correlation between Reed-Sternberg cell numbers and EBV positivity. ${ }^{13}$ Our assay might not have been sensitive enough to detect EBV in samples with low numbers of Reed-Sternberg cells, but the method used avoids the possibility of detecting low levels of EBV DNA present in residual $B$ cells in the biopsy tissue. We have shown that in 25 of the 26 cases examined the EBV genomes, in each case, contained terminal fragments of identical size.
This finding correlates with clonality and therefore suggests that the infected population has arisen from a single infected cell. This, in turn, supports the idea that EBV is involved in the pathogenesis of Hodgkin's disease in these cases.

In one case we could not detect a single discreet fragment containing the terminal repeat sequences. The most likely explanation for this is that the infected cells (either B cells or Reed-Sternberg cells) are not clonal with respect to EBV.

The EBV DNA sequences from 30 of the positive cases were subtyped into type $A$ or type $B$ viruses using the PCR. All were type A viruses. This result indicates that type $B$ viruses, which have been detected more frequently in patients with immunosuppression than in normal controls, ${ }^{34}$ are not overrepresented in Hodgkin's disease tumours.

The results of this study support the hypothesis that Hodgkin's disease is a heterogeneous condition with different aetiologies in different age groups. ${ }^{17}$ The finding that EBV is present in tumours from most paediatric and older cases strengthens the argument that EBV is involved in the pathogenesis of these cases. The pattern of EBV infection is not necessarily identical in these two age groups. We speculate that de novo infection is important in the paediatric group; reactivation of latent infection, possibly as a result of declining $T$ cell immunity, would seem more likely in the older patients. The observation that most Hodgkin's disease tumours from patients infected with the human immunodeficiency virus (HIV) are also EBV positive ${ }^{935}$ provides some support for an association between decreased $\mathrm{T}$ cell immunity and EBV positivity, although it is possible that other interactions are involved in the HIV positive cases. ${ }^{35}$

The low level of EBV positivity in young adults, particularly in those with HDNS, suggests that other factors are involved in these cases. This is particularly exciting as it is in this group that there is most epidemiological evidence for a transmissable agent. Risk factors suggestive of lack of early social contact have been found in the young adult peak incidence group, suggesting that delayed exposure to a common infectious agent may be involved. ${ }^{36}$ Clustering of Hodgkin's disease cases is also most likely to occur in cases aged under 35 years and in HDNS. ${ }^{18} 37$ We are currently investigating the possibility that other viruses are involved in this group.

The possibility that EBV genome positivity is associated with an unfavourable clinical outcome should also be evaluated further as age over 50 years, HIV positivity, and HDMC, rather than HDNS, are all indicators of a poor prognosis. $^{38-40}$

This work was supported by the Leukaemia Research Fund. We thank Kathy Higginson for help with the collection of clinical material and Maisie Riddell for assistance with preparation of the manuscript.

1 Henle W, Henle G. Epstein Barr virus related serology in Hodgkin's disease. National Cancer Institute Monograph 1973;36:79-84.

2 Hesse J, Levine PH, Ebbesen P, Connelly RR, Mordhorst 
CH. A case control study on immunity to two EpsteinBarr virus-associated antigens, and to herpes simplex virus and adenovirus in a population-based group of patients with Hodgkin's disease in Denmark, 1971-73. In $J$ Cancer 1977;19:49-58.

3 Evans AS, Gutensohn M. A population-based case-control study of EBV and other viral antibodies among persons with Hodgkin's disease and their siblings. Int J Cancer 1984;34:149-57.

4 Mueller N, Evans A, Harris NL, et al. Hodgkin's disease and Epstein-Barr virus. Altered antibody pattern before diagEpstein-Barr virus. Altered antibody p
nosis. $N$ Engl J Med 1989;320:689-95.

5 Weiss LM, Strickler JG, Warnke RA, Purtilo DT, Sklar J. Epstein-Barr viral DNA in tissues of Hodgkin's disease. Epstein-Barr viral DNA in tiss
Am J Pathol 1987;129:86-91.

6 Staal SP, Ambinder R, Beschorner WE, Hayward GS, Mann R. A survey of Epstein-Barr virus DNA in lymphoid tissue. Frequent detection in Hodgkin's disease. $A m$ J Clin Pathol 1989;91:1-5.

7 Weiss LM, Movahed LA, Warnke RA, Sklar J. Detection of Epstein-Barr viral genomes in Reed-Sternberg cells of Hodgkin's disease. N Engl J Med 1989;320:502-6.

8 Herbst $\mathrm{H}$, Tippelmann G, Anagnostopoulos I, et al. Immunoglobulin and $\mathrm{T}$-cell receptor gene rearrangements in Hodgkin's disease and $\mathrm{Ki}$-1-positive anaplastic ments in Hodgkin's disease and Ki-1-positive anaplastic large cell lymphoma: Dissociation betwe

9 Uccini S, Monardo F, Ruco LP, et al. High frequency of Epstein-Barr virus genome in HIV-positive patients with Hodgkin' disease. Lancet 1989;i:1458.

10 Anagnostopoulos I, Herbst H, Niedobitek G, Stein H. Demonstration of monoclonal EBV genomes in Hodgkin's disease and KI-1-positive anaplastic large cell lymphom by combined Southern blot and in situ hybridization. Blood 1989;74:810-16.

11 Boiocchi M, Carbone A, De Re V, Dolcetti R. Is the EpsteinBarr virus involved in Hodgkin's disease? Tumor 1989;75:345-50.

12 Libetta CM, Pringle JH, Angel CA, Craft AW, Malcolm AJ Lauder I. Demonstration of Epstein-Barr viral DNA in formalin-fixed, paraffin-embedded samples of Hodgkin's disease. $J$ Pathol 1990;161:255-60.

13 Gledhill S, Gallagher A, Jones D, et al. Viral involvement in Hodgkin's disease: Detection of clonal type A EBV genomes in tumour samples. $B r J$ Cancer (in press)

14 Wu TC, Mann RB, Charache P, et al. Detection of EBV gene expression in Reed-Sternberg cells of Hodgkin's disease. Int $J$ Cancer 1990;46:801-4.

15 Pallesen G, Hamilton-Dutoit SJ Rowe M, Young LS Expression of Epstein-Barr virus latent gene products in tumour cells of Hodgkin's disease. Lancet 1991;337: tumour

16 Lukes RJ, Craver LF, Hall TC, Rappaport H, Ruben P. Report of the nomenclature committee. Cancer Res 1966;26:1311.

17 MacMahon B. Epidemiology of Hodgkin's disease. Cancer Res 1966;26:1189-200.

18 Alexander FE, McKinney PA, Williams J, Ricketts TJ Cartwright RA. Epidemiological evidence for the 'twodisease hypothesis' in Hodgkin's disease. Int J Epidemiol (In press).

19 Young LS, Yao QY, Rooney CM, et al. New type B isolates of Epstein-Barr virus from Burkitt's lymphoma and from normal individuals in endemic areas. $J$ Gen Virol 1987;68:2853-62.

20 Jarrett RF, Gledhill S, Qureshi F, et al. Identification of human herpesvirus 6-specific sequences in two patients with
21 Andiman W, Gradoville L, Heston L, et al. Use of cloned probes to detect Epstein-Barr viral DNA in tissues of patients with neoplastic and lymphoproliferative diseases. $J$ Infect Dis 1983;148:967-77.

22 Epstein MA, Achong BA, eds. The Epstein-Barr virus: recent advances. New York: John Wiley, 1986:1-11.

23 Frizzera G. The clinico-pathological expressions of EpsteinBarr virus infection in lymphoid tissues. Virchows Arch (Pathol Anat) 1987;53:1-12.

24 Zutter MM, Martin PJ, Sale GE, et al. Epstein-Barr virus lymphoproliferation after bone marrow transplantation. Blood 1988;72:520-9.

25 Nalesnik MA, Jaffe R, Starzl TE, et al. The pathology of postransplant lymphoproliferative disorders occurring in the setting of cyclosporine A-prednisone immunosuppression. Am J Pathol 1988;133:173-92

26 Hamilton-Dutoit SJ, Pallesen G, Karkov J, Skinhoj P, Franzmann MB, Pedersen C. Identification of EBV-DNA in tumour cells of AIDS-related lymphomas by in situ hybridisation. Lancet 1989;i:554-5.

27 Sternas L, Middleton T, Sugden B. The average number of molecules of Epstein-Barr nuclear antigen 1 per cell does not correlate with the average number of Epstein-Bart virus (EBV) DNA molecules per cell among different clones of EBV-immortalized cells. J Virol 1990;64: 2407-10.

28 Arrand JR, Rymo L, Walsh JE, Bjorck E, Lindahl T, Griffin BE. Molecular cloning of the complete Epstein-Barr virus genome as a set of overlapping restriction endonucleas fragments. Nucleic Acids Res 1981;9:2999-3014.

29 Raab-Traub N, Flynn K. The structure of the termini of the Epstein-Barr virus as a marker of clonal cellular proliferation. Cell 1986;47:883-9.

30 Sample J, Young L, Martin B, et al. Epstein Barr virus type 1 and 2 differ in their EBNA 3a, EBNA 3b and EBNA 3c genes. J Virol 1990;64:4084-92.

31 Payne RW, Lane PW, Ainsley AE, et al. Genstat $V$ References manual. Oxford: Clarendon Press, 1987.

32 Bignon YJ, Bernard D, Cure H, et al. Detection of Epstein Barr virus genomes in lymph nodes of Hodgkin's disease patients. Mol Carcinog 1990;33:9-11.

33 Herbst $\mathrm{H}$, Niedobitek $\mathrm{G}$, Kneba M, et al. High incidence of Epstein-Barr virus genomes in Hodgkin's disease. $A m \mathrm{~J}$ Pathol 1990;137:13-18.

34 Sixbey JW, Shirley P, Chesney PJ, Buntin DM, Resnick L. Detection of a second widespread strain of Epstein-Bar virus. Lancet 1989;ii:761-5.

35 Uccini S, Monardo F, Stoppacciaro A, et al. High frequency of Epstein-Barr virus genome detection in Hodgkin's disease of HIV-positive patients. Int J Cancer 1990; 46:581-5.

36 Gutensohn NM. Social class and age at diagnosis of Hodgkin's disease: New epidemiologic evidence for the "two-disease hypothesis". Cancer Treat Rep 1982;66: "two-dis

37 Alexander FE, Williams J, McKinney PA, Ricketts TJ Cartwright RA. A specialst leukaemia/lymphoma registry in the UK. Part 2: Clustering of Hodgkin's disease. $\mathrm{Br}$ Cancer 1989;60:948-52.

38 Gobbi PG, Cavalli C, Federico M, et al. Hodgkin's disease prognosis: A directly predictive equation. Lance 1988;i:675-8.

39 Walker A, Schoenfeld ER, Lowman JT, Mettlin CJ, MacMillan J, Grufferman S. Survival of the older patient compared to the younger patient with Hodgkin's disease. Cancer 1990;65:1635-40.

40 Serrano M, Bellas C, Campo E, et al. Hodgkin's disease in patients with antibodies to human immunodeficiency virus. Cancer 1990;65:2248-54. 